http://dx.doi.org/10.5012/bkcs.2014.35.9.2630

\title{
Anodic Performances of Surface-Treated Natural Graphite for Lithium Ion Capacitors
}

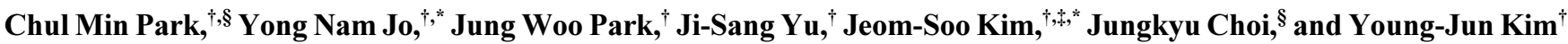 \\ ${ }^{\dagger}$ Advanced Batteries Research Center, Korea Electronics Technology Institute, Seongnam, Gyeonggi 463-816, Korea \\ *E-mail:jyn@keti.re.kr \\ *Department of Chemical Engineering, Dong-A University, Pusan 604-714, Korea. *E-mail: JSenergy@dau.ac.kr \\ ${ }^{\S}$ Department of Chemical and Biological Engineering, Korea University, Seoul 136-713, Korea \\ Received March 21, 2014, Accepted May 14, 2014
}

\begin{abstract}
The surface of natural graphite was modified by the use of hydrogen peroxide and evaluated as an anode material for lithium ion capacitors (LICs). The surface treatment was carried out under various ultrasonic conditions of 200,300 , and $400 \mathrm{~W}$, which were applied to a mixture of natural graphite and hydrogen peroxide solution for $1 \mathrm{~h}$. While the bulk structure was maintained, the hexagonal symmetry and physical properties of natural graphite, such as BET surface area, tap density, and particle size, were affected by the surface treatment. FT-IR and XPS measurements confirmed the signature of $\mathrm{C}=\mathrm{O}$ on the surface of graphite samples after treatment. Both the pristine and surface-treated graphites showed a similar reversible capacity of $370 \mathrm{mAhg}^{-1}$, and the coulombic efficiency of surface-treated graphite decreased with higher ultrasonic energies $(89.1 \%$, $89.0 \%$, and $88.0 \%$ for 200,300 , and $400 \mathrm{~W}$ ) comparing with pristine graphite $(89.4 \%)$. The capacity retention of LICs was greatly improved with the treated natural graphite. The graphite treated under the ultrasonic energy of $300 \mathrm{~W}$ and pristine natural graphite showed capacity retention of $77.5 \%$ and $42.9 \%$, implying that the surface treatment was an effective method for the improvement of natural graphite as an anode material for LICs.
\end{abstract}

Key Words : Lithium ion capacitor, Natural graphite, Surface treatment, Hydrogen peroxide, Carbonyl group

\section{Introduction}

The lithium ion capacitor (LIC) is a hybrid type of capacitor that combines an anode used in a lithium ion battery (LIB) with an activated carbon electrode in electric double layer capacitors (EDLC). The attractive merit of the LIC is the higher energy density compared to a conventional EDLC, which is due to the electrochemical characteristics of the carbonaceous materials used as anode materials in the former. ${ }^{1-3}$ Most carbonaceous materials used in the LIB, such as graphite (natural and artificial), soft carbons, and hard carbons, can also be used for the LIC. Among them, natural graphite is the most advantageous for anodes because of the low and flat electrochemical reaction voltage with lithium (0.1-0.2 V vs. $\mathrm{Li} / \mathrm{Li}^{+}$), high storage capacity (about $360 \mathrm{mAhg}^{-1}$ ), and competitive cost. However, natural graphite has detrimental drawbacks for use as an anode material for the LIC, including poor cyclability and low power density. ${ }^{4-7}$

To improve the cycle performance of graphite, many efforts have been focused on modification of the graphite surface, because the physicochemical properties of the solid/ electrolyte interface (SEI) formed on the surface during the charge process affect the cyclic performance of graphite. ${ }^{8-10}$ The representative method for surface modification is thermal oxidation or mild oxidation for inducing oxygen bonding on the surface. Peled et al. reported that the surface modified by mild oxidation retarded the degradation of $\mathrm{Li}_{\mathrm{x}} \mathrm{C}_{6}$ by stabilizing the SEI. ${ }^{11}$ Further, it has been reported that the SEI formed on thermally oxidized graphite surfaces acts as a molecular sieve to prevent the access of electrolytes and co- intercalation of solvents, thus reducing irreversible capacity and enhancing the cycle life of graphite..$^{12,13}$

In this work, we propose a simple method for uniform mild oxidation of natural graphite using hydrogen peroxide $\left(\mathrm{H}_{2} \mathrm{O}_{2}\right)$ with ultrasonic energy. The physicochemical properties of $\mathrm{H}_{2} \mathrm{O}_{2}$-treated natural graphite samples were investigated with various analysis tools and methods, including the Barret-Joyner-Halenda (BJH) analysis, particle size analysis, scanning electron microscopy (SEM), Fourier transform infrared (FT-IR) analysis, X-ray photoelectron spectroscopy (XPS), and X-ray diffraction (XRD). The surface-treated samples showed improved electrochemical cycle performance without any drawbacks-the functional group formed on the surface of graphite by the $\mathrm{H}_{2} \mathrm{O}_{2}$ treatment was proposed to be the reason for this improvement. Eventually, the effect of mild oxidation using $\mathrm{H}_{2} \mathrm{O}_{2}$ was evaluated in the LIC full cell.

\section{Experimental}

Natural graphite (S7, Poscochemtec, Korea) was treated by using an unmodified hydrogen peroxide solution (assay $40 \%$, Daejung) while applying various ultrasonic energies. S7 (10 g) was immersed in hydrogen peroxide solution (100 $\mathrm{mL})$, and then, each ultrasonic energy $(200,300$, and $400 \mathrm{~W})$ was applied for $1 \mathrm{~h}$. The treated S7 was then filtered and dried in an oven at $80{ }^{\circ} \mathrm{C}$ for $12 \mathrm{~h}$.

The physical properties of graphite were measured using a Micromeritics Tristar II 3020 for Brunauer-Emmett-Teller (BET) surface area, a particle size analyzer (PSA, NIKKISO S3500) for particle size distribution mapping, and an Autotap 
scanner for tap density. The morphology and structure of graphite powders were evaluated with a focused ion beam combined with a scanning electron microscope (FIB-ESEM, FEI Qunta 3D FEG) and X-ray diffraction (XRD, PANalytical Empyrean). The functional groups on the surface of graphite were analyzed by FT-IR spectroscopy (Bruker VERTEX70) and XPS (Thermo Scientific K alpha).

The electrochemical properties of graphite were measured using a two-electrode type glass half-cell. Working electrodes were prepared by coating with slurries containing graphite (96 wt \%) and binder (SBR/CMC) dissolved in de-ionized water on the $\mathrm{Cu}$ foil that was used as a current collector. The electrodes were pressed to have an electrode density of $1.3 \mathrm{~g} \mathrm{~cm}^{-3}$ and dried under vacuum at $120^{\circ} \mathrm{C}$ for $12 \mathrm{~h}$. The half cells were assembled in a dry room using polyethylene as a separator, $\mathrm{Li}$ foil as a counter electrode, and electrolyte consisting of $1.3 \mathrm{M} \mathrm{LiPF}_{6}$ in ethylene carbonate (EC)/dimethyl carbonate (DMC) (1:3 by volume ratio, PANAX Etec) with a vinylene carbonate (VC, $1 \mathrm{wt} \%)$ as an functional additive. The cells were charged (lithiation) and discharged (delithiation) under a constant current of $72 \mathrm{mAg}^{-1}$ between the voltage window of 0.01 and $1.5 \mathrm{~V}\left(v s . \mathrm{Li} / \mathrm{Li}^{+}\right)$.

The anodic performances of graphite for LICs were evaluated using a lab-designed four-electrode type glass full cell. The cathode was prepared by coating a slurry containing activated carbon (92 wt \%) and polyvinylidene fluoride (PVdF, 8 wt \%) dissolved in $N$-methylpyrrolidone (NMP) on Al mesh. The anodes were prepared by coating the slurry containing graphite $(80 \mathrm{wt} \%)$, the conductive agent $(10$ wt \%), and the binder (PVdF, $10 \mathrm{wt} \%$ ) dissolved in NMP on $\mathrm{Cu}$ mesh. Cathodes and anodes were pressed to have electrode densities of $0.5 \mathrm{~g} \mathrm{~cm}^{-3}$ and $1.0 \mathrm{~g} \mathrm{~cm}^{-3}$, respectively, and then dried under vacuum at $120^{\circ} \mathrm{C}$ for $12 \mathrm{~h}$. The full cells were assembled in a dry room using polyethylene as the separator, Li foil as reference and counter electrodes, and the same electrolyte as used in the half-cell test. Pre-doping was carried out under a constant voltage of $0.01 \mathrm{~V}\left(v s . \mathrm{Li} / \mathrm{Li}^{+}\right)$, and the amount of $\mathrm{Li}^{+}$allowed to intercalate into graphite under the limitation of controlling at $80 \%$ of the theoretical capacity of graphite $\left(372 \mathrm{mAhg}^{-1}\right)$. Initial conditioning was performed by cycling the cells at a $0.1 \mathrm{C}$ rate $\left(37 \mathrm{mAg}^{-1}\right)$ between the voltage window of 1.5 and $3.9 \mathrm{~V}$ for 3 iterations. The cycle performance was evaluated at the current of $10 \mathrm{C}$ rate $\left(3600 \mathrm{mAg}^{-1}\right)$ for 9000 cycles. All electrochemical measurements were carried out with a SERIES 4000 cycler (MACCOR) at $23^{\circ} \mathrm{C}$.

\section{Results and Discussion}

The surface morphologies of pristine and surface-treated graphites were observed by FIB-ESEM, as shown in Figure 1. Pristine graphite (S7) has a rounded shape and narrow particle size distribution. Although the $\mathrm{H}_{2} \mathrm{O}_{2}$-treated samples retained the round shape of pristine $\mathrm{S} 7$, the surface became rough and small particles loosened and fell off the surface with an increase in the applied ultrasonic energy. It appears
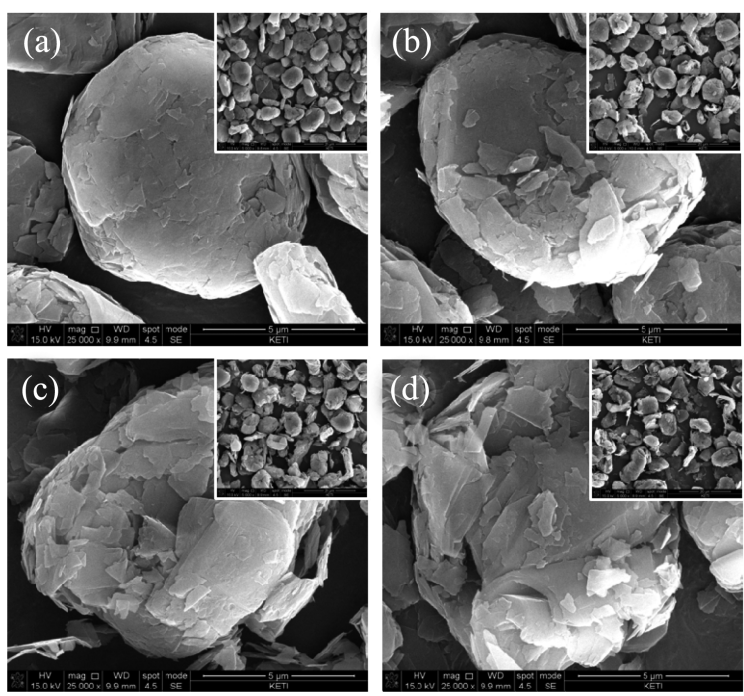

Figure 1. FIB-ESEM images for (a) S7, (b) surface-treated natural graphite by hydrogen peroxide under ultrasonic energy of $200 \mathrm{~W}$, (c) $300 \mathrm{~W}$, and (d) $400 \mathrm{~W}$, respectively. Inset images show the shape of many particles at lower magnification $(\times 5,000)$.

that the ultrasonic irradiation shakes an S7 particle vigorously and the small flakes fall apart from the main body of S7. Physical properties such as surface area, particle size, and tap density were measured to verify whether the changed surface morphologies affected the physical properties of the graphites. As the ultrasonic energy became stronger, the surface area increased while the tap density decreased. S7 was originally prepared from the crumpling of flake-type graphite under high-speed rotating conditions. ${ }^{14}$ Through this process, the shape of the graphite particles changed to irregular spheres (similar to a potato). The applied ultrasonic energy loosened entangled flakes from the crumpled body, and some of the small flakes were detached from the main particle. Increases in surface area were the result of the surface roughness, which was generated by ultrasonic irradiation, while the small flakes caused decreased tap density. The

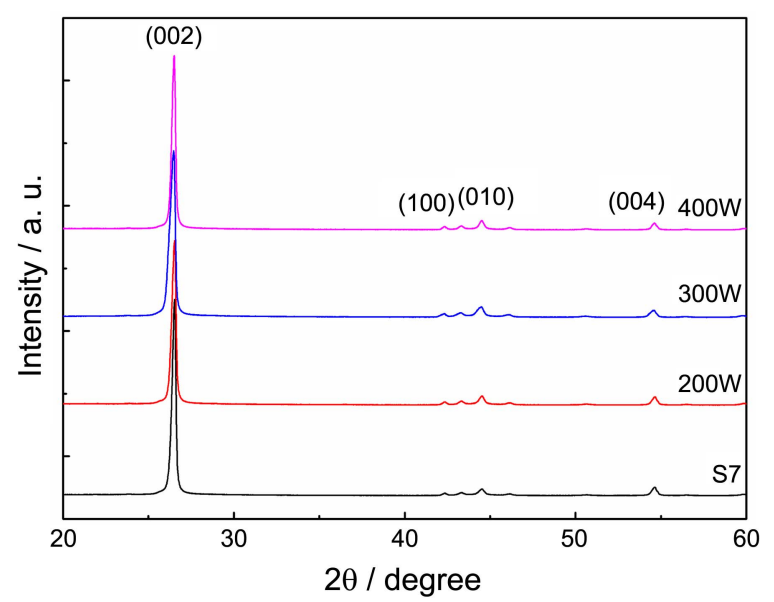

Figure 2. Powder XRD patterns for $\mathrm{S} 7$ and surface-treated natural graphites; four peaks are indexed to (002), (100), (010), and (004), which indicate hexagonal symmetry. 


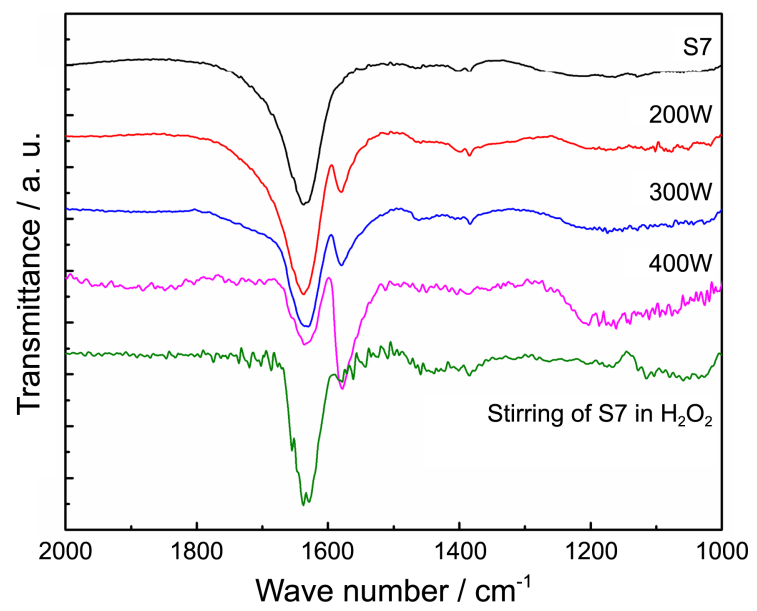

Figure 3. FT-IR spectra for $\mathrm{S} 7$ and surface-treated natural graphites; the newly formed peak at $1,580 \mathrm{~cm}^{-1}$ was clearly detected and matched with the carbonyl group $(\mathrm{C}=\mathrm{O})$.

bulk structures of the graphite samples were analyzed using powder XRD. According to the powder XRD patterns in Figure 2, all reflections were well matched with a typical graphite structure with hexagonal symmetry. There was no signature for the formation of a secondary phase and/or impurity phase on the surface treated samples. This implied that the applied ultrasonic energy was strong enough to change the morphology of the graphite samples, but not enough to change the bulk structure.

From the viewpoint of surface chemistry, the $\mathrm{H}_{2} \mathrm{O}_{2}$-treated graphites were analyzed by FT-IR and XPS. FT-IR measurements were carried with the $\mathrm{KBr}$ pellet technique, using the prepared sample-to- $\mathrm{KBr}$ ratio of $1 / 100$ by weight. The spectroscopic results are shown in Figure 3. The peak around $1,620 \mathrm{~cm}^{-1}$ was observed for all graphite samples, while a new peak appeared at around $1,580 \mathrm{~cm}^{-1}$ only in the spectra of the surface-treated samples. The peak around $1,620 \mathrm{~cm}^{-1}$ was assigned to a hydroxyl group, which could be explained by the native existence of an $\mathrm{OH}$ group on the surface of the graphites. The newly formed peak around $1,580 \mathrm{~cm}^{-1}$ was assigned to a carbonyl group..$^{15,16}$ The intensity of this peak increased with the ultrasonic energy, which meant that the amount of $\mathrm{C}=\mathrm{O}$ bonding formed on the graphite surface is proportional to the power of applied ultrasonic energy. To identify the role of ultrasonic energy, a sample was prepared under the same treatment conditions but without ultrasonic energy. This sample did not show any peak around $1,580 \mathrm{~cm}^{-1}$, which indicated that ultrasonic energy is a key parameter to induce $\mathrm{C}=\mathrm{O}$ bonding.

The oxidation state of oxygen existing on the surface of graphite was analyzed by XPS; the measured peaks of $\mathrm{O}_{1 \mathrm{~s}}$ are shown in Figure 4 to confirm the formation of carbonyl groups on the graphite surface. The peaks of all samples were normalized to the highest value of 100 . For binding energies greater than $532 \mathrm{eV}$, the peaks of all the samples were similar, whereas the peaks below $532 \mathrm{eV}$ were different (Fig. 4(a)). The intensity of the peak around $530 \mathrm{eV}$ increased as the power of the applied ultrasonic energy was increased. The (a)

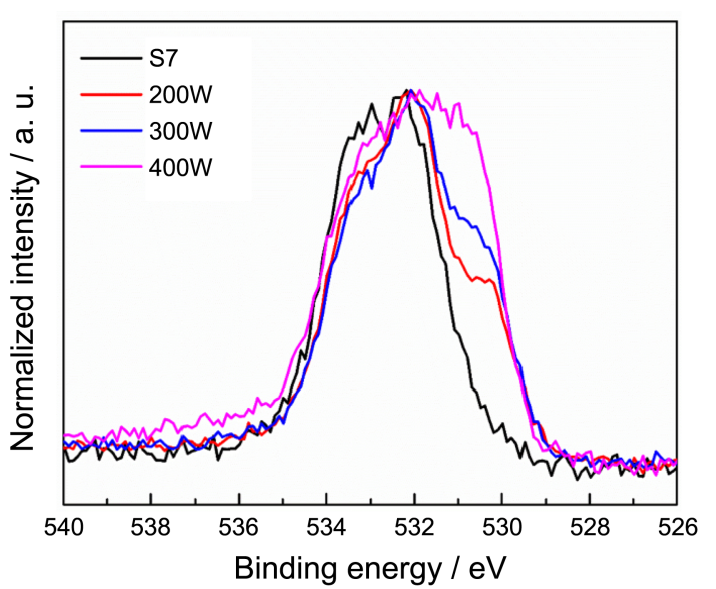

(b)

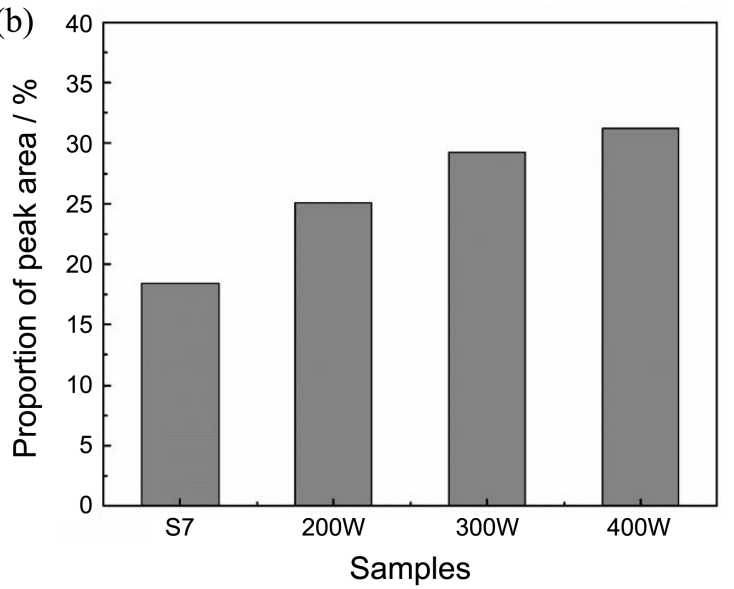

Figure 4. (a) XPS spectra of $\mathrm{O}_{1 \mathrm{~s}}$. (b) The proportion of deconvoluted peak around $530 \mathrm{eV}$ for $\mathrm{S} 7$ and surface-treated natural graphites.

binding energy of $\mathrm{O}_{1 \mathrm{~s}}$ around $530 \mathrm{eV}$ could be associated with the $\mathrm{C}=\mathrm{O}$ bonding in the carbonyl or carboxyl functional groups, with $533 \mathrm{eV}$ coming from the single bonding of oxygen. ${ }^{17,18}$ This indicated that the newly formed oxygen bonding on the surface is related to $\mathrm{C}=\mathrm{O}$. To compare the intensity of the peak around $530 \mathrm{eV}$, the peaks were deconvoluted and the portion of peak area around $530 \mathrm{eV} v s$. the total peak area is compared in Figure 4(b). This portion linearly increased with increasing ultrasonic energy, which agrees with the FT-IR analysis. From these results, we can confirm the formation of carbonyl groups on the surface of graphites by $\mathrm{H}_{2} \mathrm{O}_{2}$ treatment under ultrasonic irradiation.

The electrochemical properties of the S7 series were evaluated using glass half-cells. Additive-free electrolyte was used for verifying the effects of $\mathrm{H}_{2} \mathrm{O}_{2}$ treatment. In this study, the discharge capacity and efficiency were similar between samples S7 (371.0 $\left.\mathrm{mAhg}^{-1}, 89.1 \%\right), 200 \mathrm{~W}$ (372 $\left.\mathrm{mAhg}^{-1}, 89.0 \%\right)$, and $300 \mathrm{~W}\left(371.5 \mathrm{mAhg}^{-1}, 89.2 \%\right)$. Only the $400 \mathrm{~W}$ sample showed different values of discharge capacity (366.9 $\left.\mathrm{mAhg}^{-1}\right)$ and efficiency $(88 \%)$, as shown in Figure 5(a). After $\mathrm{H}_{2} \mathrm{O}_{2}$ treatment, the reversible charge capacity did not change $\left(\sim 370 \mathrm{mAhg}^{-1}\right)$, indicating that the bulk structure was not affected by this treatment. In consideration of physical properties, ultrasonic energies of up to 

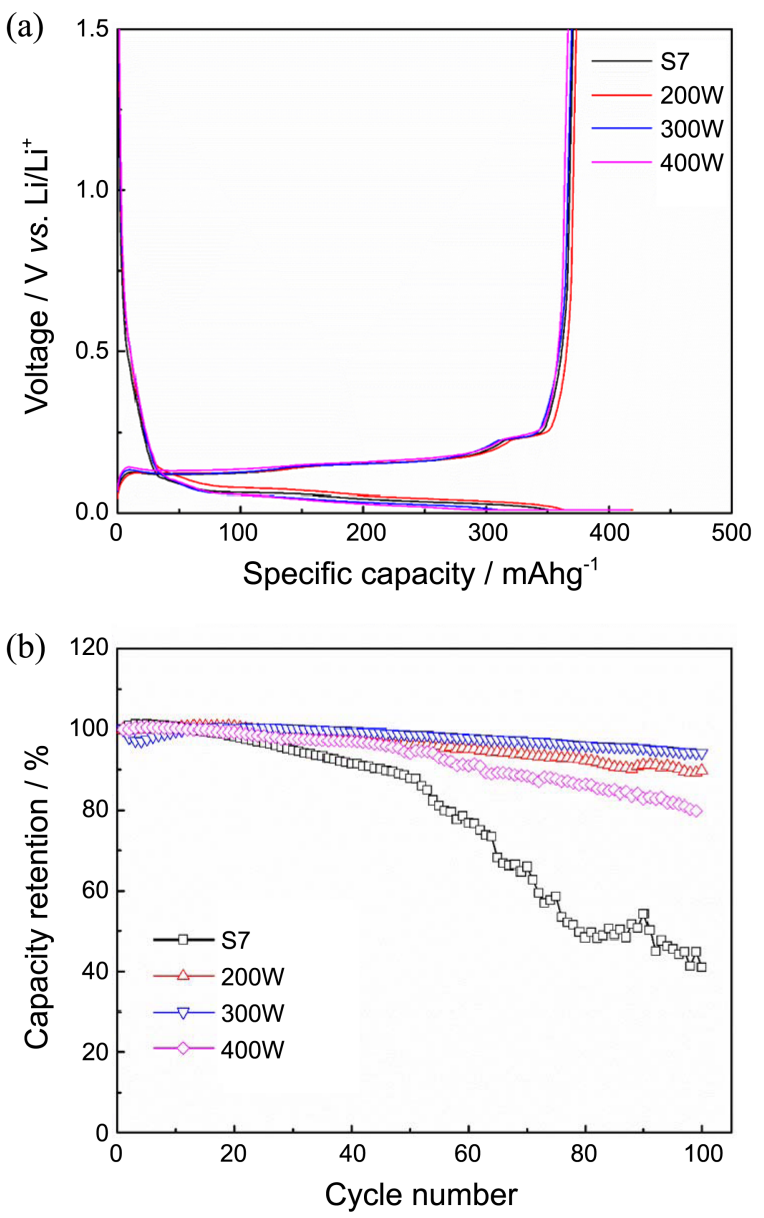

Figure 5. (a) Charge-discharge profiles for $\mathrm{S} 7$ and surface-treated natural graphite at first cycle. (b) Cyclic performances tested in a half-cell during 100 cycles.

$300 \mathrm{~W}$ were not enough to change the graphite, resulting in similar coulombic efficiencies. When the energy reached $400 \mathrm{~W}$, the surface treatment effect was counterbalanced by the increased surface area, consuming lithium ions during the charge cycle. Sample $400 \mathrm{~W}$ displayed the lowest efficiency of $88 \%$. Unlike the first charge-discharge cycle, there was a clear difference in the cycle performance characteristics. All $\mathrm{H}_{2} \mathrm{O}_{2}$-treated samples showed good capacity retention results, but the capacity of pristine graphite decayed rapidly during electrochemical cycling, as shown in Figure 5(b). Among the $\mathrm{H}_{2} \mathrm{O}_{2}$-treated $\mathrm{S} 7$ samples, $300 \mathrm{~W}$ showed the highest retention rate of $94 \%$ after 100 cycles. $300 \mathrm{~W}$ showed good electrochemical properties and was selected for a long-term cycle test with the full cell configuration using an activated carbon electrode as the cathode.

Lithium doping is a necessary process prior to operation of the LIC. During the doping process, lithium ions move into the graphite anode from lithium foil used as a source of lithium ion. The cell voltage increases by decreasing the anode voltage, while the cathode voltage remains unaffected. Conventional doping methods using a constant potential were applied to a beaker cell with four electrodes. The electrolyte with VC 1 wt $\%$ was used to verify the effect of surface
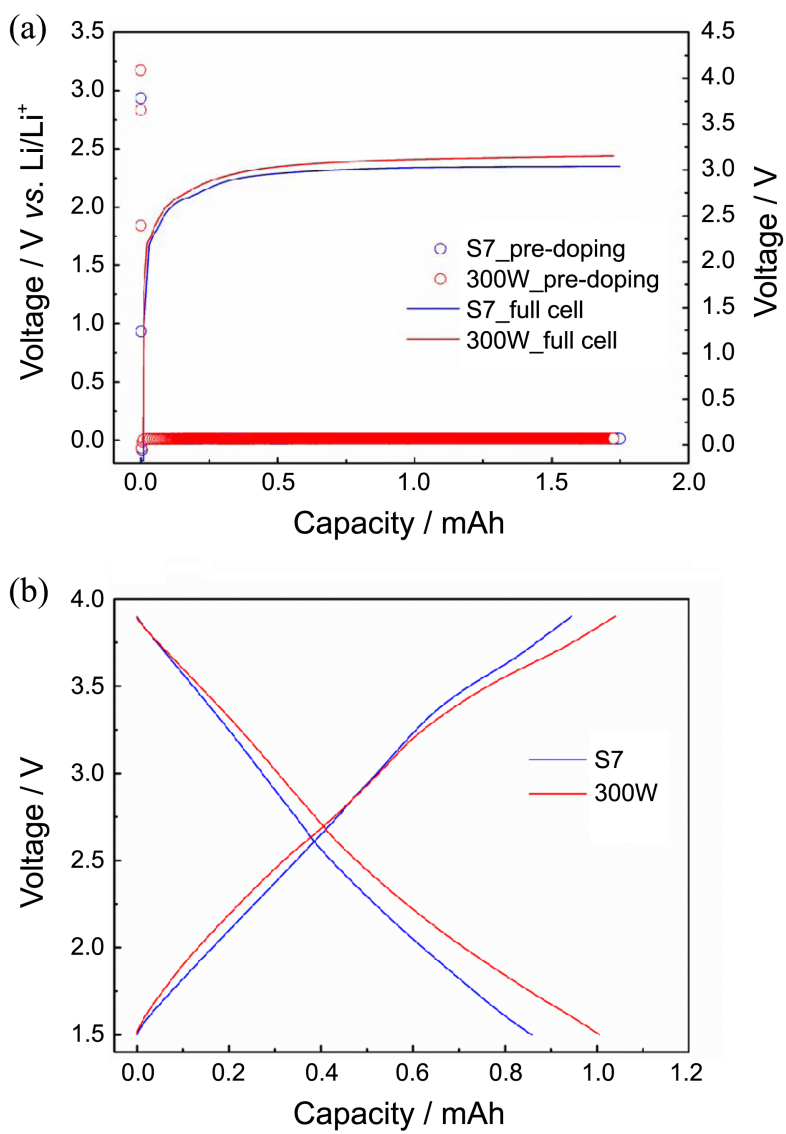

Figure 6. (a) Voltage changes for the anode and full cell made using S7 and surface-treated natural graphite under the ultrasonic energy of $300 \mathrm{~W}$ during pre-doping. (b) The voltage profiles of the full cell during the 1 st cycle after pre-doping.

treatment on full cell performances. Figure 6(a) shows the controlled anode voltages $\left(0.01 \mathrm{~V} v s\right.$. $\left.\mathrm{Li} / \mathrm{Li}^{+}\right)$and corresponding full cell voltages of S7 and $300 \mathrm{~W}$ anode, respectively. The doping capacities for S7 and $300 \mathrm{~W}$ were very close because the electrodes were prepared with matched amount of active materials. Although similar amounts of lithium were doped in both cases, the initial charge capacities were different by $10 \%(0.1 \mathrm{mAh})$, as shown in Figure 6(b). The capacity difference increased following discharge. While $300 \mathrm{~W}$ delivered a discharge capacity of $1.0 \mathrm{mAh}$, the pristine graphite $\mathrm{S} 7$ showed $0.86 \mathrm{mAh}$ as a discharge capacity $\mathrm{H}_{2} \mathrm{O}_{2}$ treatment $(300 \mathrm{~W})$ improved the coulombic efficiency of natural graphite (S7) from $91 \%$ to $96 \%$. Therefore, surface modification with $\mathrm{H}_{2} \mathrm{O}_{2}$ is effective not only to lithium doping but also to the first cycle efficiency.

In Figure 7, the $\mathrm{H}_{2} \mathrm{O}_{2}$-treated graphite at $300 \mathrm{~W}$ showed increased capacity retention compared to the pristine graphite. Minimal differences were observed up to 500 cycles between samples, although the pristine graphite (S7) lost retention more rapidly beyond the 500th cycle. Most LIBs use a graphite anode with VC added electrolyte and are evaluated up to 500 cycles for examining the cycle performance characteristics. The VC effect is clearly observed here, i.e., $96 \%$ capacity retention after 500 cycles for $\mathrm{S} 7$ when compared to 


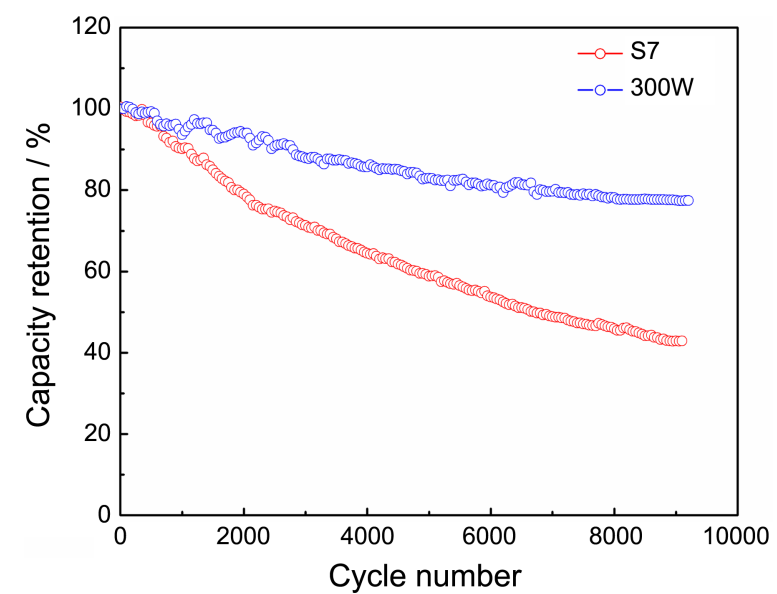

Figure 7. Cyclic performances tested in the full cell for S7 and surface-treated natural under the ultrasonic energy of $300 \mathrm{~W}$.

the result $(41 \%$ after 100 cycles) without $\mathrm{VC}$ shown in Figure 5(b). After 9000 cycles, $300 \mathrm{~W}$ holds $77 \%$ of the initial capacity, while $\mathrm{S} 7$ retains only $43 \%$. In consideration of $\mathrm{VC}$ additives, the functional electrolyte alone is not sufficient to ensure capacity retention for long-term cycling in the case of pristine graphite (S7). From these results, we confirm that $\mathrm{H}_{2} \mathrm{O}_{2}$ treatment under applied ultrasonic energy is an effective method to modify the surface of graphite by forming $\mathrm{C}=\mathrm{O}$ bonding, which enhances the electrochemical properties of graphite as an LIC anode material.

\section{Conclusion}

For improving the cycle performance, natural graphite was treated with hydrogen peroxide under applied ultrasonic energy and tested as an anode for LICs. The resulting chemical bonding of carbonyl groups that formed on the graphite surface was confirmed by FT-IR and XPS measurements. The surface-treated natural graphite under an applied ultrasonic energy of $300 \mathrm{~W}$ was tested as an anode for an LIC; the capacity retention after 9000 cycles was $77 \%$, which demonstrates a much improved cyclic performance compared to the pristine natural graphite, which shows a capacity retention of $43 \%$.

Acknowledgments. This research was supported by the Conversing Research Program through the Ministry of Science, ICT and Future Planning, Korea (2013K000290).

\section{References}

1. Simon, P.; Gogotsi, Y. Nat. Mater. 2008, 7, 845.

2. Park, M.-S.; Lim, Y.-G.; Kim, J.-H.; Kim, Y.-J.; Cho, J.; Kim, J.-S. Adv. Energy Mater. 2011, 1, 1002.

3. Kossyrev, A. P.; Oljaca, M.; Passerini, S.; Winter, M.; Balducci, A. J. Power Sources 2011, 196, 8836.

4. Cao, W. J.; Zheng, J. P. J. Power Sources 2012, 213, 180.

5. Kim, J.-H.; Kim, J.-S.; Lim, Y.-G.; Lee, J.-G.; Kim, Y.-J. J. Power Sources 2011, 196, 10490.

6. Sivakkumar, S. R.; Nerkar, J. Y.; Pandolfo, A. G. Electrochim. Acta 2010, 55, 3330.

7. Sivakkumar, S. R.; Milev, A. S.; Pandolfo, A. G. Electrochim. Acta 2011, 56, 9700.

8. Ng, S. H.; Vix-Guterl, C.; Bernardo, P.; Tran, N.; Ufheil, J.; Buqa, H.; Dentzer, J.; Gadiou, R.; Spahr, M. E.; Goers, D.; Novak, P. Carbon 2009, 47, 705.

9. Park, M.-S. Kim, J.-H.; Jo, Y.-N.; Oh, S.-H.; Kim, H.; Kim, Y.-J. J. Mater. Chem. 2011, 21, 17960.

10. Fu, L. J.; Liu, H.; Li, C.; Wu, Y. P.; Rahm, E.; Holze, R.; Wu, H. Q. Solid State Sci. 2006, 8, 113 .

11. Peled, E.; Menachem, C.; Bar-Tow, D.; Melman, A. J. Electrochem. Soc. 1996, 143, L4.

12. Prem Kumar, T.; Manuel Stephan, A.; Thayananth, P.; Subramanian, V.; Gopukumar, S.; Renganathan, N. G.; Raghavan, M.; Muniyandi, N. J. Power Sources 2001, 97-98, 118.

13. Koresh, J.; Soffer, A. J. Chem. Soc. Faraday Trans. I 1980, 76 2457.

14. Ohzeki, K.; Saito, Y.; Golman, B.; Shinohara, K. Carbon 2005, 43, 1673.

15. Shen, W.; Li, Z.; Liu, Y. Recent Patents on Chemical Engineering 2008, $1,27$.

16. Li, Z.; Fredericks, P. M.; Rintoul, L.; Ward, C. R. Int. J. Coal and Geology 2007, 70, 87.

17. Cuervo, M. R.; Asedegbega-Nieto, E.; Díaz, E.; Ordónez, S.; Vega, A.; Dongil, A. B.; Rodríguez-Ramos, I. Carbon 2008, 46, 2096.

18. Puziy, A. M.; Poddubnaya, O. I.; Socha, R. P.; Gurgul, J.; Wisniewski, M. Carbon 2008, 46, 2113. 